\title{
Influence of Milling Type on Tef Injera Quality
}

Yoseph Assefa ${ }^{\mathrm{a}, *}$, Shimelis Emire ${ }^{\mathrm{a}}$, Marina Villanueva ${ }^{\mathrm{b}}$, Workineh Abebe $^{\mathrm{c}}$, Felicidad Ronda $^{\mathrm{b}}$

${ }^{a}$ Addis Ababa Institute of Technology, School of Chemical Engineering, Food Engineering Stream, P.O. Box 385, Addis Ababa, Ethiopia

${ }^{\mathrm{b}}$ College of Agricultural and Forestry Engineering, University of Valladolid, Av. Madrid 57, 34004 Palencia, Spain

${ }^{c}$ Ethiopian Institute of Agricultural Research, P.O. Box 2003, Addis Ababa, Ethiopia

\begin{abstract}
Injera is an Ethiopian flat bread that is mostly made from tef flour. Injera making on an industrial scale holds a significant economic and social interest but requires a thorough study of how the process variables affect the product quality. The aim of this work was to investigate the effects of mill type (hammer, disc, and blade) on injera sensory quality and starch digestibility. The application of software for the determination of injera quality descriptors and its comparison with visual human eye evaluation was also established. Injera made with disc mill flour had higher overall acceptability (6.6) than that obtained from hammer mill (4.2) and blade mill (4.1) flours. The injera made with blade mill flour obtained the lowest rapidly available glucose and rapidly digestible starch. The outcome of introducing software for the determinations of injera number of eyes was found effective; its difference with human eye determination was insignificant.
\end{abstract}

Keywords: Tef; Milling; Injera quality; Sensory quality evaluation software

\section{Introduction}

Injera is leavened, flat round Ethiopian traditional bread made from cereals such as tef and sorghum (Pasqualone, 2018). Its surface has essentially evenly spaced gas holes that make up a 
honeycomb-like structure formed due to the production of gas during fermentation and baking. Injera has a shiny and smooth bottom surface. As stated by the work of Yetneberk et al. (2004), good injera is expressed as soft and roll-able. A slight sourness is a characteristic taste of injera. Because injera is leavened bread made from natural gluten-free flour, it has great potential for commercial production internationally.

Injera prepared from the flour of tef [Eragrostistef (Zucc.) Trotter], a tiny, millet-like grain, is the most preferred (Yetneberk et al., 2004).Tef is an Ethiopian indigenous tropical cereal crop, and it has been cultivated for many years in the Ethiopian highlands (Viswanath, 2012). It is the main staple in the country and is mostly used to make injera. Tef represents $24 \%$ of the grain crop area in Ethiopia and $17.6 \%$ of the grain production (Central Statistical Authority, 2015).

The whole tef grain is ground to flour for making injera, local beverage porridges and soup and unleavened bread (Bultosa and Taylor, 2004).The sizes of the seed are very small, ranging from 0.6-1 mm diameter and 1-1.7 mm long with 1000 seed weight averaging $0.3-0.4 \mathrm{~g}$ and 150 grains of tef have comparable weight with almost one seed of wheat (Diskstra, 2008).Tef grain products are nutritionally rich because they are eaten as whole grain with the significantly higher content of fiber, carbohydrate (USDA, 2007), iron, zinc and calcium than wheat, barley and sorghum (Abebe et al., 2007). Due to the absence of gluten and gluten-like proteins, tef has recently been popular globally particularly, as a "healthy food", making it right for celiac disease patients (Spaenij-Dekking et al., 2005), and in addition, because of other dietary benefits such as the slow-release of carbohydrate constituents, it is useful for diabetic patients (Abebe and Ronda, 2014).

Depending on the mechanical forces and temperature during the grinding process, various milling or grinding methods have been introduced to produce different flours with different 
particle size and starch damage level(Kadan, Bryant \& Miller, 2008).In Ethiopia, mostly disk millisused to grindtef grain in the homemade injera process. However, other types of mills have not been checked for their better quality of injera. The effect of milling technique on the sensory attributes of whole-wheat pan bread was studied by Kihlberg et al. (2004). The result showed that technique of milling had a greater influence on bread sensory quality and on the slice area than did the baking technique and farming system. However, techniques of milling on sensory attributes of tef injera remain lacking.

The number, size, and distribution of holes (commonly called eyes) on the injerasurface represent one of the most important quality attributes of injera (Yetneberk et al., 2005). However, determinations of these injera quality descriptors are very difficult due to the nature of its uncountable eyes, which lead to subjective quality evaluation. Due to this, the injera standard, which was developed by the Ethiopian standard agency, lacks these quality attributes in measurable form. Currently, as injera industrialization is emerging, a systematic way of injera quality determination (injera number of eyes, eye size, and eye distributions) is mandatory for maintaining uniform quality.

Therefore, the objective of this research was to investigate the effects of three different mill types (Hammer, Disc, and blade) on injera sensorial quality and starch digestibility and to compare a software-based evaluation of injera quality descriptors with visual evaluation.

\section{Materials and methods}

\subsection{Materials}

Based on its popularity among Ethiopian tef farmers and users, the Qouncho tef variety (DZ-Cr387) was selected and obtained from the DebreZeit Agricultural Research Center of the 
Ethiopian Institute of Agricultural Research (EIAR). The tef sample was hermetically stored in a cool and dry place using polyethylene bag. Before milling, the tef grain was cleaned by sifting.

\subsection{Tef milling}

Tef grain was milled using three types of mills to obtain the whole flour of the tef sample. The first one was the Hammer mill (HM) (Perten 120, Finland) with a $0.8 \mathrm{~mm}$ sieve fitted inside as part of the mill, the second mill was the stone-disk mill (DM) (cottage tef grain-milling, Denmark) and the third mill was the blade mill (BM) (Nutri Bullet NB-101B, China).One kg of sample was milled by HM and DM for 7 minutes, and five $\mathrm{kg}$ of samples were milled by BM for 7 minutes at ambient temperature.

\subsection{Injera preparation}

The tef injera samples were prepared according to Parker et al. (1989) and Zegeye (1997). An amount of starter (Ersho) equal to $60 \mathrm{ml}$ was initially added for each $\mathrm{kg}$ of flour. Ersho is a small amount of batter kept from previous dough to start first stage fermentation (Parker et al., 1989). The tef flour was mixed 2:3 (w/w) with potable water and kneaded by hand in a bowl until obtaining a homogenous mixture in the traditional way. The dough was allowed to spontaneously ferment for 60 hours at room temperature $(30 \pm 5){ }^{\circ} \mathrm{C}$ in an injera baking household in Addis Ababa, Ethiopia. After this primary fermentation, 10\% of the dough was mixed 1:3 (v/v) with boiling water and heated for 15 min with continuous stirring. The hot cooked dough (absit) was then mixed back into the fermenting dough, and sufficient potable water was added to make a batter. The batter was left covered for 2 hours for secondary fermentation. Additional water was added to thin and form the right consistency of the batter. Finally, half a liter of batter was

poured onto the hot clay griddle in a circular form. After 2-3 min of cooking using traditional electric injera baking equipment, the injera was removed and placed in a basket.

\subsection{Flour characterization}




\subsubsection{Proximate analysis}

Tef grain was milled using a stone-disc mill and flour proximate composition (Crude protein, fat, ash, fiber) was determined using AACC methods (AACC, 2000). Total carbohydrate was determined by difference to $100 \%$ (FAO, 2003).

\subsubsection{Flour color}

Flour color was evaluated according to the methods of Abebe, Collar \& Ronda (2015). The spectrophotometer was used for flour color measurements. CIE $\mathrm{L}^{*} \mathrm{a} * \mathrm{~b}$ coordinates were used to obtain the result by using the D65 standard illuminant and the $2^{\circ}$ standard observer. The hue (h) and the chroma $\left(\mathrm{C}^{*}\right)$ were calculated from Eqs. (1) and (2) respectively.

$$
\begin{aligned}
& h=\tan ^{-1}\left(b^{*} / a^{*}\right) \cdots \ldots \ldots \ldots(1) \\
& C^{*}=\left(\left(a^{*}\right)^{2}+\left(b^{*}\right)^{2}\right)^{1 / 2} \ldots \ldots . . .
\end{aligned}
$$

\subsubsection{Particle size distribution}

According to Sivaramakrishnan, Senge, and Chattopadhyay (2003), the particle size distribution was evaluated by passing the tef flour through an automatic standard sieve shaker (Retsch, Germany) that contains 5 sieves. Sieves with the sizes of $710,500,250,125$ and $90 \mu \mathrm{m}$ were used. The percentage fraction of the sample retained on each sieve was measured by weighing.

\subsubsection{Damaged starch evaluation}

The damaged starch level of the tef flour samples was determined according to the AACC method (AACC, 2012) using a Megazyme starch damage kit (Megazyme International Ireland Ltd., Co., Wicklow, Ireland). Absorbance was read at $510 \mathrm{~nm}$ in a microplate reader from BIOTEKEPOCH (Izasa, Barcelona, Spain). The damaged starch level of the tef flour was determined as a percentage of the flour weight on a dry basis. 


\subsubsection{Scanning electron microscopy (SEM)}

Scanning Electron Microscope (SEM) model Quanta 200-F (FEI, Oregon, USA) equipped with an X-ray detector was used to examine the three tef flours. Samples were directly placed on stubs, and observations were done by accelerating voltage of $1.5 \mathrm{keV}$.

\subsection{Injera quality analysis}

\subsubsection{Starch fractions analysis}

The method by Englyst, Kingman, and Cummings (1992) was used to measure in vitro starch digestibility of tef injera with the modifications by Englyst et al.(1999); Englyst et al. (2000). The hydrolyzed glucose at $20 \mathrm{~min}$ (G20) and $120 \mathrm{~min}$ (G120) and the total glucose (TG) were measured by the glucose oxidase colorimetric method. The free sugar glucose (FGS) content was measured by a separate test according to the procedure proposed by Englyst et al. (2000). Rapidly digested starch $(\mathrm{RDS})=0.9 *(\mathrm{G} 20-\mathrm{FGS})$, slowly digestible starch $(\mathrm{SDS})=0.9 *$ $(\mathrm{G} 120-\mathrm{G} 20)$, resistant starch $(\mathrm{RS})=0.9 *(\mathrm{TG}-\mathrm{G} 120)$, for total starch, $(\mathrm{TS})=0.9 *(\mathrm{TG}-$ FGS) and rapidly available glucose of the sample (RAG) $=$ G20 were calculated. As used by Abebe, Collar, and Ronda (2015), the starch digestibility rate index (SDRI) was computed from the percentage of RDS in TS in the flours.

\subsubsection{Descriptive sensory analysis}

The sensory evaluation was conducted by a panel trained according to Einstein (1991). The selected panelists were tested for their ability to detect basic tastes (Jellinek 1985). The selected panel comprised 10 people, as recommended by Stone and Sidel (1985). They were females and males, who were students at Addis Ababa University. Nine injera quality descriptors were used for evaluation: color, taste, odor, texture (degree of softness), injera number of eyes, eye size, eye distribution (eye uniformity), and top and bottom surface (degree of being powdery and sticky); 
overall acceptability was also evaluated. A score sheet was prepared using the selected descriptors. Each one of the attribute was evaluated using a 10-point numerical scale (0-9) anchored on both sides with verbal descriptions (i.e., $0=$ unpleasant, $9=$ pleasant) to allow the panel to score the intensity on a framed common scale. Good sensory practices were followed according to Lawless and Heymann (1999). Injera samples were presented to the panelists on a tray at ambient temperature $\left(\approx 25^{\circ} \mathrm{C}\right)$ within 3-4 hr after baking. A glass of drinking water was used for rinsing between samples.

\subsubsection{Software based injera quality evaluation}

Photos of injera samples were acquired and imported into ImageJ software (version 2) determining injera number of eyes, eye size, and eye distributions. Injera photos were converted to gray scale using Image J software, and the software converted the image into detectable form to easily recognize the injera eyes.

\subsection{Statistical analysis}

Analysis of variance was performed on the data to establish significant $(p<0.05)$ differences between the samples. All analyses were done in duplicate, and the descriptive categories were converted to numerical scores. The scores were then subjected to analysis of variance using SPSS statistical software (Version 16), and the means of duplicate results were compared by Tukey's Honestly significant difference test.

\section{Results and discussion}

\subsection{Flour characteristics}

\subsubsection{Proximate composition}

Tef sample has $10.9 \pm 1.2 \%$ of moisture and $2.13 \pm 0.01 \%$ of ash content. Baye (2014) presented a similar result of ash content (2.8). Wheat (1.6) and sorghum (1.6) have lesser amounts of ash than 
that of the tef sample. The higher ash content of the sample could be due to its higher fiber content, as tef flour comes from whole grain (Abebe \& Ronda 2014). However, the fat $(2.53 \pm 0.29 \%)$, protein $(10.99 \pm 0.29 \%)$ and carbohydrate $(81.35 \pm 0.21 \%)$ contents of the sample agreed with those of the report that was compiled by Baye (2014) with $2.5 \%$ of fat, $11.0 \%$ of protein and $80 \%$ of carbohydrate in dry matter. The higher contribution of bran to the whole tef grain flour composition could be explained by the smaller size of the tef grain (Bultosa, 2007), which gives a higher surface area of bran per unit amount of grain, in comparison with whole wheat. However, the crude protein content of the sample is slightly higher than sorghum (8.3) and comparable to wheat (11.7).

\subsubsection{Flour color}

The color coordinates of the tef flours obtained from the three mills are summarized in Table 1. Although the values of the coordinates show significant differences, the color differences, $\Delta \mathrm{E}$, that resulted were low enough to be appreciated by the human eye $(<5)$, except for the blade mill flour, which depicted significantly lower lightness than the flours from the two other mills. The effect of mill type on the color of the tef flours varied significantly; this variation may come from the difference in milling principles among the three mills. Lightness $\left(\mathrm{L}^{*}\right)$, hue angle $\left(\mathrm{h}^{*}\right)$ and chroma $\left(\mathrm{c}^{*}\right)$ of samples varied significantly among HM, DM, and BM (Table 1). DMF (87.7) had significantly higher lightness, which was followed by HMF (85.3) and BMF (71.0).Such an effect of mill type could probably be related to the degree of breaking and pulverization of the bran of the tef grains. The hue angle of the three flour varied significantly in the order BMF (68.9) < HMF (71.4) < DMF (72.7). This seems slightly different from the work of Abebe et al. (2015) in the case of cyclotech sample mill (L* 83.2, $\left.\mathrm{h}^{*} 85.3\right)$ and disk mill (L* 81.7, $\mathrm{h}^{*}$ 85.2). However, the chroma of flours varied significantly in the order DMF $(15.1)<$ 
HMF (17.1) < BMF (18.5). However, the chroma of flour from the disk mill agreed with the report by Abebe et al. (2015) for cyclotech and disk mill (14.6 and 15.4).

Table 1. Tef flour color

\begin{tabular}{cccccc}
\hline Mill & $\mathrm{L}^{*}$ & $\mathrm{a}^{*}$ & $\mathrm{~b}^{*}$ & $\mathrm{~h}^{*}$ & $\mathrm{c}^{*}$ \\
\hline HMF & $85.3 \pm 0.0^{\mathrm{b}}$ & $5.45 \pm 0.0^{\mathrm{b}}$ & $16.2 \pm 0.0^{\mathrm{b}}$ & $71.4 \pm 0.04^{\mathrm{b}}$ & $17.1 \pm 0.0^{\mathrm{b}}$ \\
DMF & $87.7 \pm 0.0^{\mathrm{c}}$ & $4.50 \pm 0.0^{\mathrm{a}}$ & $14.5 \pm 0.01^{\mathrm{a}}$ & $72.7 \pm 0.03^{\mathrm{c}}$ & $15.1 \pm 0.0^{\mathrm{a}}$ \\
BMF & $71.0 \pm 0.02^{\mathrm{a}}$ & $6.68 \pm 0.01^{\mathrm{c}}$ & $17.3 \pm 0.01^{\mathrm{c}}$ & $68.9 \pm 0.04^{\mathrm{a}}$ & $18.5 \pm 0.0^{\mathrm{c}}$ \\
\hline
\end{tabular}

HMF, DMF, and BMF stand for flour from hammer, disk and blade mills, respectively. Data are expressed as the mean \pm standard deviations; different superscripts in the same column indicate statistically significant differences $(\mathrm{P}$ $<0.05)$. $\mathrm{L}^{*}, \mathrm{a}^{*}$, and $\mathrm{b}^{*}$ are CIE coordinates, $\mathrm{h}=$ hue, and $\mathrm{C}^{*}=$ chroma.

\subsubsection{Particle size distribution}

Particle size distributions of the three tef flour (HMF, DMF, and BMF) showed a significant difference in percent retention at all sieve sizes used, except at $710 \mu \mathrm{m}$ (Table 2). In particular, at 500 and $250 \mu \mathrm{m}$ sieve, 6.7 and $56.2 \%$ of BMF was retained, respectively, which was significantly higher than that of HMF (0.2 and 18.9\%) and DMF (0.2 and 2.9\%). However, DMF was retained significantly in a lower amount than that of HMF on $250 \mu \mathrm{m}$ sieve. Flour retention on $125 \mu \mathrm{m}$ sieve varied significantly in the order BMF $(31.1 \%)<\mathrm{DMF}(35.4 \%)<\mathrm{HMF}(44.5 \%)$. For sieve size $(90$ and $<90 \mu \mathrm{m})$, flour particles varied significantly in the order BMF $(5.9$ and $0 \%)<\mathrm{HMF}$ $(10.9,25.4)<\operatorname{DMF}(28.9,32.6)$, respectively. The reason for having different particle size distributions is perhaps due to the difference in milling procedures among the three mills. The hammer mill crushed the grain repeatedly until it passed through the sieve that was fitted inside the mill. Tef grain was ground between two stone-discs in the case of disc mill. The blade mill had rotary blades to grind the grain.

\subsubsection{Damaged starch}


The damaged starch level of tef flour obtained from the three mills varied significantly in the order HMF $(1.50 \%)<\operatorname{BMF}(2.66 \%)<\operatorname{DMF}(5.11 \%)$ (Table 2). The inverse relationship between flour particle size and damaged starch was noted on DMF: as particle size decreased $(<90 \mu \mathrm{m})$, the damaged starch level increased (5.11\%). This agrees with a report by Abebe, Collar and Ronda (2015). However, due to the difference in milling principle among the three mills (HM, DM, BM), this relationship was not seen on HMF. The reason for having different starch damage levels was a result of grinding conditions such as milling force (Nowakowski et al., 1986 and Tran et al., 2011) and temperature and grain moisture content (Li et al., 2014).

Table 2. Particle size distribution and damaged starch level of tef flour

\begin{tabular}{cccccccc}
\hline & \multicolumn{5}{c}{ Particle size distribution (\% retained) } & Damaged Starch \\
\cline { 2 - 6 } Mill & $710(\mu \mathrm{m})$ & $500(\mu \mathrm{m})$ & $250(\mu \mathrm{m})$ & $125(\mu \mathrm{m})$ & $90(\mu \mathrm{m})$ & $<90(\mu \mathrm{m})$ & \\
\hline HMF & $0.1 \pm 0^{\mathrm{a}}$ & $0.2 \pm 0.1^{\mathrm{a}}$ & $18.9 \pm 1.1^{\mathrm{b}}$ & $44.5 \pm 0.6^{\mathrm{c}}$ & $10.9 \pm 0.4^{\mathrm{b}}$ & $25.4 \pm 0.3^{\mathrm{b}}$ & $1.50 \pm 0.05^{\mathrm{a}}$ \\
$\mathrm{DMF}$ & $0.0 \pm 0^{\mathrm{a}}$ & $0.2 \pm 0.1^{\mathrm{a}}$ & $2.90 \pm 0.3^{\mathrm{a}}$ & $35.4 \pm 0.1^{\mathrm{b}}$ & $28.9 \pm 1.3^{\mathrm{c}}$ & $32.6 \pm 0.7^{\mathrm{c}}$ & $5.11 \pm 0.14^{\mathrm{c}}$ \\
$\mathrm{BMF}$ & $0.1 \pm 0^{\mathrm{a}}$ & $6.7 \pm 0.3^{\mathrm{b}}$ & $56.2 \pm 0.3^{\mathrm{c}}$ & $31.1 \pm 0.1^{\mathrm{a}}$ & $5.90 \pm 0.1^{\mathrm{a}}$ & $0.00 \pm 0.0^{\mathrm{a}}$ & $2.66 \pm 0.01^{\mathrm{b}}$ \\
\hline
\end{tabular}

HMF, DMF, and BMF stand for flour from hammer mill, flour from disk mill and flour from blade mill, respectively. Data are expressed as the mean \pm standard deviations; different superscripts in the same column indicate statistically significant differences $(\mathrm{P}<0.05)$.

\subsubsection{Scanning electron microscopy (SEM)}

The effects of mill type on tef grain were seen by scanning electron microscope (SEM) (fig. 4.1). Starch granule pulverizations and the release of individual starch granules were seen on flour from $\mathrm{HM}$ and DM. However, the extent of pulverization on DMF was more as its average particle size is smaller than that of $\mathrm{HMF}$ and BMF. This result agrees with a report by Abebe et al. (2015).As to the release of individual starch granules on BMF seen less than DMF and HMF, its larger particle size explains the difference. In case of disc mill, the milling discs were the 
most effective in releasing individual starch granules than the rotary blades of blade mill. Less release of individual starch granules was noted during the use of rotary blades compared to the hammer. According to Jane et al. (2003), the damage, which forms pinholes on granule surface and channels inside the granules, is probably from the effect of endogenous enzymes hydrolysis inside the grain.

\subsection{Injera characteristics}

\subsubsection{In vitro starch digestibility}

The three tef injeras had similar content of resistant starch (RS) and total starch (TS) (Table 3).The effects of mill type on starch hydrolysis of tef injera were significantly varied; HMI leads to higher FSG, RAG, and RDS than that of BMI. However, there was no significant difference in RAG, RDS and SDS content between DMI and HMI except for FSG, and DMI and BMI. Tef grain milled repeatedly until the flour pass-through the $0.8 \mathrm{~mm}$ sieve size that was fitted on the hammer mill. This difference in milling principle between blade and hammer mill justifies the results. However, this principle was not reflected on DMI, which had higher damaged starch with smaller particle size. This agreed with Li et al. (2014), who asserted that cereal flour starch digestibility is highly influenced by the degree of damaged starch and flour particle size. Due to starch fragmentation, damaged starch granules have larger relative surface area for enzyme attack than intact native starch granules. However, it has not yet been proven whether the same principle applies to the digestibility of gelatinized starch in cooked cereal flour, but the SDS of BMI (24.9) was significantly higher than that of HMI (6.3). The inverse correlation between flour particle size and RAG, RDS and SDS were seen on BMI, as its flours (BMF) have a higher mean particle size lead to the lower content of RAG and RDS, with the higher content of the SDS of BMI. These agree with the reports by Mahasukhonthachat et al. (2010) and Al-Rabadi et 
al. (2009). It has been understood that the flour starch digestibility is controlled by enzyme diffusion inside flour particles. However, with similar particle sizes, the rate of starch digestion was seen to be different between barley and sorghum flours (Mahasukhonthachat et al., 2010) and between sorghum flours from the hammer and cryogenic mill (Al-Rabadi et al., 2009). As reported by Ronda et al. (2015) the RAG (82.7) and the RDS (74.3) content of wheat bread was significantly higher than that of HMI $(65.7,58.9)$, DMI $(61.5,55.3)$ and BMI $(52.6,47.3)$. According to Miao et al. (2015), the health implication of moderate postprandial glycemic and insulinemic response due to slowly digestible starch (SDS) implies that foods with a high amount of SDS may provide wide health advantages by reducing common chronic diseases related to diet, such as diabetes and pre-diabetes, cardiovascular diseases, and obesity (metabolic syndromes). The SDRI of BMI (64.6) varied greatly from HMI (75.8). This may be a result of the difference in particle size of the tef flour; however, the same principle was lacking in justifying DMI (72.3), which was not significantly different from HMI and BMI.

Table 3. Starch fractions, FSG, RAG, and SDRI, expressed in percentage referring to the dry matter

\begin{tabular}{cccccccc}
\hline Mill & FSG & RAG & RDS & SDS & RS & TS & SDRI \\
\hline HMI & $0.30 \pm 0.04^{\mathrm{b}}$ & $65.7 \pm 2.6^{\mathrm{b}}$ & $58.9 \pm 2.3^{\mathrm{b}}$ & $6.3 \pm 2.3^{\mathrm{a}}$ & $8.8 \pm 5.2^{\mathrm{a}}$ & $74.0 \pm 5.2^{\mathrm{a}}$ & $75.8 \pm 3.0^{\mathrm{b}}$ \\
DMI & $0.05 \pm 0.07^{\mathrm{a}}$ & $61.5 \pm 3.6^{\mathrm{ab}}$ & $55.3 \pm 3.2^{\mathrm{ab}}$ & $15.5 \pm 3.2^{\mathrm{ab}}$ & $5.8 \pm 1.3^{\mathrm{a}}$ & $76.6 \pm 1.3^{\mathrm{a}}$ & $72.3 \pm 2.9^{\mathrm{ab}}$ \\
BMI & $0.07 \pm 0.01^{\mathrm{a}}$ & $52.6 \pm 0.0^{\mathrm{a}}$ & $47.3 \pm 0.0^{\mathrm{a}}$ & $24.9 \pm 0.0^{\mathrm{b}}$ & $1.0 \pm 1.7^{\mathrm{a}}$ & $73.2 \pm 1.7^{\mathrm{a}}$ & $64.6 \pm 1.5^{\mathrm{a}}$ \\
\hline
\end{tabular}

HMI, DMI, and BMI stand for injera from hammer mill, injera from disk mill and injera from blade mill, respectively. $\mathrm{FSG}=$ free sugar, $\mathrm{RAG}=$ rapidly available glucose, $\mathrm{RDS}=$ rapidly digestible starch, $\mathrm{SDS}=$ slowly digestible starch, $\mathrm{RS}=$ resistant starch, TS = total starch, and SDRI = starch digestion rate index. Data are expressed as the mean \pm standard deviations; different superscripts in the same column indicate statistically significant differences $(\mathrm{P}<0.05)$. 

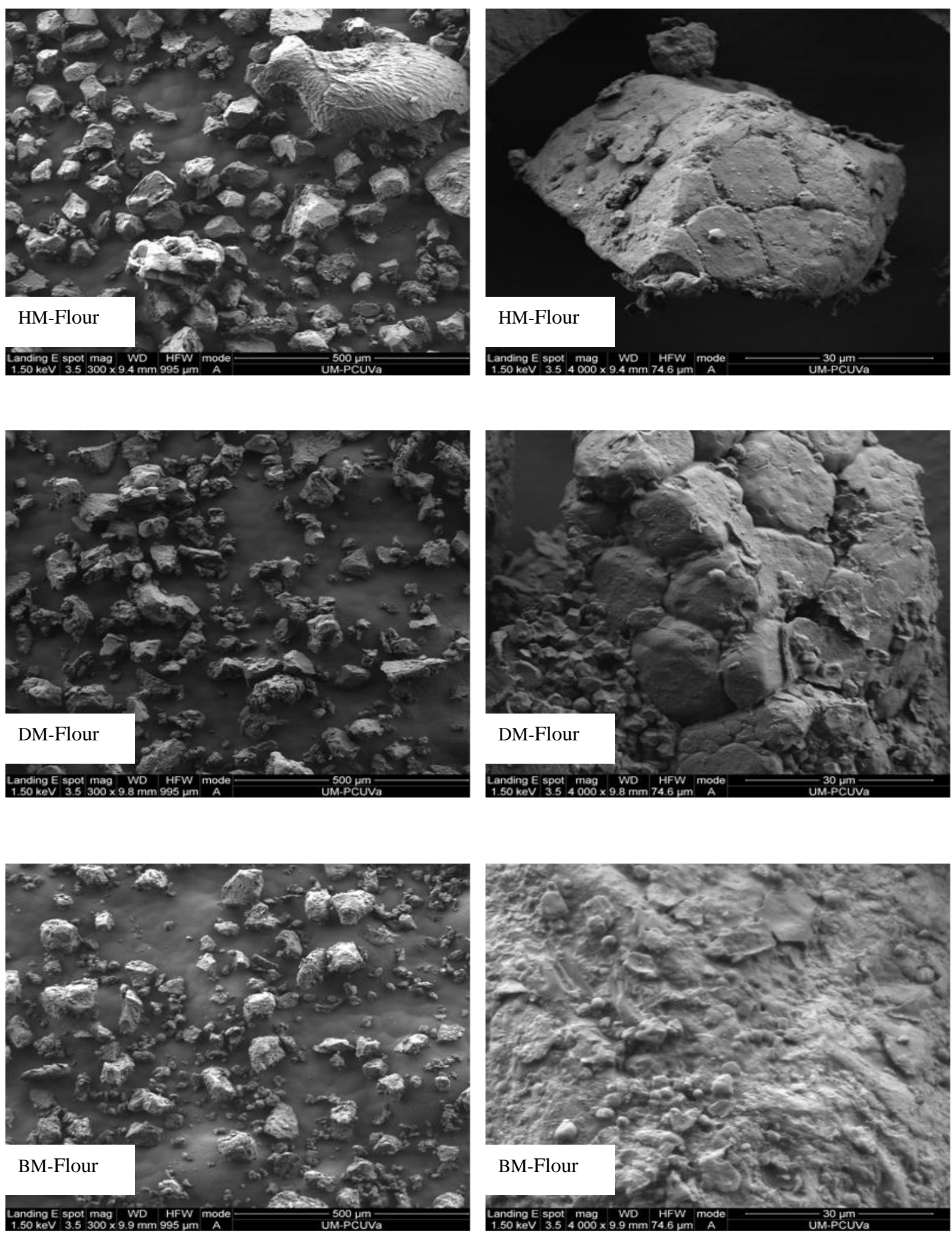

Fig. 1. SEM pictures of tef flours studied. HM: Hammer ill, DM: Disc mill, BM: Blade mill 


\subsubsection{Sensory result}

The impacts of mill type (HM, DM, and BM) on sensorial quality of tef injera (HMI, DMI, and BMI) are presented in table 4. There was no significant difference between HMI, DMI and BMI in color, odor, taste, number of eyes, eye distribution and the top and the bottom surface of injera. The three injeras were described as white in color, acceptable in odor, slightly sour in taste with many eyes and regular eye distribution with a non-sticky and non-powdery top and bottom surface. However, a significant difference in the intensity of texture (degree of softness), eye size and overall acceptability werefound.DMI (6.9) had a significantly softer texture than that of HMI (4.10) and BMI (3.5). However, HMI and BMI had significantly higher scores of eye size, 6.0 and 6.1 respectively, than DMI (1.6).

Table 4. Sensory panel responses of injera prepared from tef flour using hammer, disc and blade mill.

\begin{tabular}{cccc}
\hline & \multicolumn{3}{c}{ Injera intensity } \\
\cline { 2 - 4 } Descriptors & HMI & DMI & BMI \\
\hline Color & $7.1 \pm 1.6^{\mathrm{a}}$ & $7.2 \pm 1.8^{\mathrm{a}}$ & $6.2 \pm 0.8^{\mathrm{a}}$ \\
Odor & $6.6 \pm 1.2^{\mathrm{a}}$ & $5.6 \pm 1.9^{\mathrm{a}}$ & $4.3 \pm 1.1^{\mathrm{a}}$ \\
Taste & $5.3 \pm 1.5^{\mathrm{a}}$ & $6.4 \pm 1.7^{\mathrm{a}}$ & $5.3 \pm 0.7^{\mathrm{a}}$ \\
Texture & $4.1 \pm 15^{\mathrm{a}}$ & $6.9 \pm 1.7^{\mathrm{b}}$ & $3.5 \pm 1.1^{\mathrm{a}}$ \\
Number of Eyes & $6.1 \pm 1.4^{\mathrm{a}}$ & $7.8 \pm 1.9^{\mathrm{a}}$ & $6.2 \pm 1.1^{\mathrm{a}}$ \\
Eye size & $6.0 \pm 1.5^{\mathrm{b}}$ & $1.6 \pm 2.2^{\mathrm{a}}$ & $6.1 \pm 1.0^{\mathrm{b}}$ \\
Eye distribution & $4.4 \pm 1.5^{\mathrm{a}}$ & $6.4 \pm 1.9^{\mathrm{a}}$ & $5.5 \pm 1.0^{\mathrm{a}}$ \\
Top and bottom surface & $6.0 \pm 1.2^{\mathrm{a}}$ & $5.4 \pm 1.8^{\mathrm{a}}$ & $5.9 \pm 1.0^{\mathrm{a}}$ \\
Overall acceptability & $4.2 \pm 1.1^{\mathrm{a}}$ & $6.6 \pm 1.8^{\mathrm{b}}$ & $4.1 \pm 1.2^{\mathrm{a}}$ \\
\hline
\end{tabular}

HMI, DMI, and BMI stand for injera from hammer mill, injera from disk mill and injera from blade mill, respectively. Data are expressed as the mean \pm standard deviations; different superscripts in the same row indicate statistically significant differences $(\mathrm{P}<0.05)$. 
The difference in injera texture and eye size may come from the difference in tef flour particle size and its impact on fermentation (De la Hera et al., 2014). This implies that the fermentation kinetics may be affected by the flour particle size distribution and level of starch damage. Hence, the overall acceptability of injera was found to be influenced by the injera texture. There was no significant difference in the intensity of injera texture, eye size and overall acceptability between HMI and BMI.

\subsubsection{Application of Software in injera quality evaluation}

ImageJ software was used for the quantification of the injera number of eyes, eye size and distribution and compared with human performance on three injeras (HMI, DMI, and BMI) (Table 5). There was no significant difference in the quantification of the injera number of eyes between human eyes and the software. The software results of the injera number of eyes (HMI$224<$ BMI- 271< DMI-298) agrees with the sensory panelists' response (HMI-6.1< BMI-6.2 < DMI-7.8).It is very difficult and takes much time to analyze the injera number of eyes, eye size, and eye distribution visually by human eye; however, the software analyzed it very quickly without any problem. The software easily converted the image of the injera sample into other forms and analyzed and reported it (Fig. S1). The software application required a quicker determination time than did visual determination. This may save time and help in manufacturing a uniform quality of injera in the manufacturing industry. In addition, the use of this software can give additional benefits to injera manufacturing countries to improve injera standards and requirements by including important injera quality attributes (number of eyes, eye size, and distribution) in measurable ways. 
Table 5. Application of software in injera quality evaluation

\begin{tabular}{ccccccc}
\hline Injera & $\begin{array}{c}\text { Total number of } \\
\text { eyes (Human } \\
\text { Eye) }\end{array}$ & $\begin{array}{c}\text { Total Number of } \\
\text { eyes per square } \\
\text { (Software) }\end{array}$ & $<1 \mathrm{~mm}(\%)$ & $1-4 \mathrm{~mm}(\%)$ & $4-7 \mathrm{~mm}(\%)$ & $7-10 \mathrm{~mm}(\%)$ \\
\cline { 5 - 7 } & $224 \pm 3.4$ & $224 \pm 4.0$ & $41.6 \pm 1.2$ & $55.2 \pm 1.4$ & $3.2 \pm 0.1$ & $0 \pm 0.0$ \\
HMI & $298 \pm 2.4$ & $298 \pm 2.4$ & $74.3 \pm 0.9$ & $20.2 \pm 1.0$ & $5.5 \pm 0.1$ & $0 \pm 0.0$ \\
DMI & $271 \pm 3.6$ & $271 \pm 3.8$ & $47.8 \pm 1.7$ & $49.1 \pm 1.1$ & $3.1 \pm 0.3$ & $0 \pm 0.0$ \\
BMI & 27.0 &
\end{tabular}

HMI, DMI, and BMI stand for injera from hammer mill, injera from disk mill and injera from blade mill respectively.

\section{Conclusions}

Differences in the mill type used to grind tef grain during injera preparation influenced the particle size distribution and damaged starch level of the tef flour and hence the final quality of injera. Although mill differences affect the color of the tef flour, the final color of the injera was not affected. This may be a result of the involvement of other unit operations that are mandatory in injera making. The variation in injera sensorial quality and starch digestibility were due to the differences in milling type and its effect on particle size distribution and the damaged starch level of tef flour. The use of DM gives smaller flour particle size with a high level of starch damage and leads to better sensorial injera quality than that of BM and HM. The use of BM leads to a larger flour particle size, which could be responsible for having lower RAG and RDS. However, it is highly important to study the relationship between damaged starch and flour particle size on cooked flour. The influence of different tef cultivars and mill types on injera quality needs to be studied.

The application of software-based injera quality evaluation to determine the number of injera eyes gave effective results, which thus can replace human manual determination. Determinations of injera eye size and distribution are the additional advantage of using software-based injera quality evaluation. 


\section{Acknowledgement}

The authors thank DebreZeit Agricultural Research Center of the Ethiopian Institute of Agricultural Research (EIAR) for providing tef variety and Addis Ababa University for supporting with facilities in this research work. The authors also thank the financial support of the Ministerio de Economía y Competitividad and the European Regional Development Fund (AGL2015-63849-C2-2-R) and the Consejería de Educacion (Junta de Castilla y Leon)/FEDER (Project VA072P17). Marina Villanueva thanks the Junta de Castilla y Leon for her doctorate grant.

\section{References}

Abebe, W., \& Ronda, F. (2014).Rheological and textural properties of tef [Eragrostis tef (Zucc.) Trotter] grain flour gels. Journal of Cereal Science, 60(1), 122-130.

Abebe, W., Collar, C., \& Ronda, F. (2015). Impact of variety type and particle size distribution on starch enzymatic hydrolysis and functional properties of tef flours. Carbohydrate polymers, $115,260-268$.

Abebe, Y., Bogale, A., Hambidge, K. M., Stoecker, B. J., Bailey, K., \& Gibson, R. S. (2007). Phytate, zinc, iron and calcium content of selected raw and prepared foods consumed in rural Sidama, Southern Ethiopia, and implications for bioavailability. Journal of Food Composition and Analysis, 20(3), 161-168.

Al-Rabadi, G. J., Gilbert, R. G., \& Gidley, M. J. (2009). Effect of particle size on kinetics of starch digestion in milled barley and sorghum grains by porcine alpha-amylase. Journal of Cereal Science, 50(2), 198-204.

American Association of Cereal Chemists (2012).Approved methods of analysis (11thed.Method: 76-31.01 (damaged starch)), 2012, AACC International; St Paul, MN.

American Association of Cereal Chemists (AACC). (2000). Approved methods of analysis. St. Paul, MN: AACC International.

Baye, K. (2014). Teff: nutrient composition and health benefits (Vol. 67). Intl Food Policy Res Inst.

Bultosa, G., \& Taylor, J. (2004). Paste and gel properties and in vitro digestibility of tef [Eragrostis tef (Zucc.)Trotter] starch. Starch-Stärke, 56(1), 20-28.

Central statistical authority (2015). Report on area and production of major crops. 2014/15 Statistical bulletin 578.

De la Hera, E., Rosell, C. M., \& Gomez, M. (2014). Effect of water content and flour particle size on gluten-free bread quality and digestibility. Food chemistry, 151, 526-531. 
Dijkstra, A., Polman, J., van Wulfften-Palthe, A., Gamboa, P. A., \& van Ekris, L. (2008).Survey on the nutritional and health aspects of teff (Eragrostis Tef).

Einstein, M. A. (1991). Descriptive techniques and their hybridization. Sensory science theory and applications in foods, 317-338.

Englyst, H. N., Kingman, S. M., \& Cummings, J. H. (1992). Classification and measurement of nutritionally important starch fractions. European journal of clinical nutrition, 46, S33-50.

Englyst, K. N., Englyst, H. N., Hudson, G. J., Cole, T. J., \& Cummings, J. H. (1999). Rapidly available glucose in foods: an in vitro measurement that reflects the glycemic response. The American journal of clinical nutrition, 69(3), 448-454.

Englyst, K., Hudson, G., \& Englyst, H. (2000).Starch analysis in food. RA Meyers (Ed.), Encyclopedia of Analytical Chemistry.

FAO/WHO, (2003). Food Energy Methods of Analysis and Conversion Factors. FAO Food and Nutrition, Rome. Paper 77

Jane, J. L., Ao, Z., Duvick, S. A., Wiklund, M., Yoo, S. H., Wong, K. S., \& Gardner, C. (2003). Structures of amylopectin and starch granules: how are they synthesized?. Journal of Applied Glycoscience, 50(2), 167-172.

Jellinek, G. (1985). Sensory evaluation of food.Theory and practice. Ellis HorwoodLtd..

Kadan, R. S., Bryant, R. J., \& Miller, J. A. (2008). Effects of milling on functional properties of rice flour. Journal of food science, 73(4).

Ketema, S. (1993). Tef (Eragrostis tef): breeding, genetic resources, agronomy, utilization and role in Ethiopian agriculture.

Kihlberg, I., Johansson, L., Kohler, A., \& Risvik, E. (2004). Sensory qualities of whole wheat pan bread-influence of farming system, milling and baking technique. Journal of Cereal Science, 39(1), 67-84.

Lawless, H. T., \& Heymann, H. (1999).Sensory Evaluation of Food. Principles and Practices,; Aspen Pulishers. Inc.: Gaithersburg, MD, USA.

Li, E., Dhital, S., \& Hasjim, J. (2014).Effects of grain milling on starch structures and flour/starch properties. Starch-Stärke, 66(1-2), 15-27.

Mahasukhonthachat, K., Sopade, P. A., \& Gidley, M. J. (2010). Kinetics of starch digestion in sorghum as affected by particle size. Journal of Food Engineering, 96(1), 18-28.

Miao, M., Jiang, B., Cui, S. W., Zhang, T., \& Jin, Z. (2015). Slowly digestible starch-a review. Critical reviews in food science and nutrition, 55(12), 1642-1657.

Nowakowski, D., Sosulski, F. W., \& Hoover, R. (1986). The effect of pin and attrition milling on starch damage in hard wheat flours. Starch-Stärke, 38(8), 253-258.

Parker, M. L., Umeta, M., \& Faulks, R. M. (1989). The Contribution of flour components to the structure of injera, an Ethiopian fermented bread made from tef (Eragrostis tef). Journal of Cereal Science, 10(2), 93-104.

Pasqualone, A. (2018). Traditional flat breads spread from the Fertile Crescent: productive process and history of baking systems. Journal of Ethnic Foods. 
Ronda, F., Abebe, W., Pérez-Quirce, S., \& Collar, C. (2015).Suitability of tef varieties in mixed wheat flour bread matrices: A physico-chemical and nutritional approach. Journal of Cereal Science, 64, 139-146.

Ronda, F., Rivero, P., Caballero, P. A., \& Quilez, J. (2012). High insoluble fibre content increases in vitro starch digestibility in partially baked breads. International journal of food sciences and nutrition, 63(8), 971-977.

Shumoy, H., \& Raes, K. (2017). In vitro starch hydrolysis and estimated glycemic index of tef porridge and injera. Food Chemistry, 229, 381-387.

Sivaramakrishnan, H. P., Senge, B., \& Chattopadhyay, P. K. (2004).Rheological properties of rice dough for making rice bread. Journal of Food Engineering, 62(1), 37-45.

Spaenij-Dekking, L., Kooy-Winkelaar, Y., \&Koning, F. (2005). The Ethiopian cereal tef in celiac disease. New England Journal of Medicine, 353(16), 1748-1749.

Stone, H., \&Sidel, J. L. (1985).Sensory Evaluation Practices Academic Press. San Diego, 2nd.

Tran, T. T., Shelat, K. J., Tang, D., Li, E., Gilbert, R. G., \&Hasjim, J. (2011).Milling of rice grains. The degradation on three structural levels of starch in rice flour can be independently controlled during grinding. Journal of agricultural and food chemistry, 59(8), 3964-3973.

USDA, (2007).National Nutrient Database for Standard Reference.Release 20.USDA.

Viswanath, N. (2012). The Hierarchy of Poor: The Tension between Favoring Smallholder Farmers or Domestic Consumers in Ethiopian Agricultural Development. Africa Policy Journal, 8, 30.

Yetneberk, S., de Kock, H. L., Rooney, L. W., \& Taylor, J. R. (2004).Effects of sorghum cultivar on injera quality. Cereal chemistry, 81(3), 314-321.

Yetneberk, S., Rooney, L. W., \& Taylor, J. (2005). Improving the quality of sorghum injera by decortication and compositing with tef. Journal of the Science of Food and Agriculture, 85(8), 1252-1258.

Zegeye, A. (1997). Acceptability of injera with stewed chicken. Food quality and preference, 8(4), 293-295. 